\title{
Improvement of learning outcome in material science through inverted classroom techniques and alternative course assessment
}

\section{Pfennig, Anja}

HTW Berlin, Universtiy of Applied Sciences HTW Berlin, Wilhelminenhofstr. 75A, 12459

Berlin, Germany

\begin{abstract}
Material Science is known to first year mechanical engineering students as one of the fundamental courses with high work load. The knowledge of the complex science of materials enables students to select appropriate engineering materials in different designs due to acquired knowledge on the correlation of materials properties, microstructure and their intended manipulation. These abilities are not well constituted in one final exam. Therefore peer-to-peer lecture film supported inverted classroom szenarios were estabilished to work in the course. These were accompanied by a newly developed moodle course following the blended learning approach that gives students the chance to cumulative accomplish micro-grades via multiple activities, such as tests, lectures, presentations, forum discussions, written homeworks and glossary entries. These grades are summed to obtain the overall course grade. Improved learing outcomes are demonstrated in high quality class discussions and most -important to students- in better grades (average 43/60=B) compared to those being assessed by one final exam only (average 39/69= $C^{+}$). The majority of students agreed on enhanced study skills when forced to study throughout the entire semester instead of learing intensely towards the end of the semester. This paper introduces the learning structure as well as graded activities, evaluates the course and compares activity results to former class results.
\end{abstract}

Keywords: material science, lecture films, peer to peer, inverted classroom, blended learning, first year students. 


\section{Grading in higher education}

Grading and reporting on student learning continue to challenge educators. To develop grading and reporting practices that provide quality information about student learning requires clear thinking, careful planning, excellent communication skills, and an overriding concern for the well-being of students: Guskey (2012). Criteria-based approaches to assessment and grading in higher education is widely and controversially discussed due to its educational effectiveness but lack of common understanding in practice. But shifting the primary focus to standards and making criteria secondary could lead to substantial progress: Sadler (2005). The educational benefits of standards-based versus the traditional scorebased grading have been quantitavely modeled by: Marbouti (2016) showing that standards-based grading is based on "the measurement of the quality of students proficiency towards achieving well defined course objectives": Heywood, (2014, p. 1514)

Because standard-based grading assesses students' achievement of the course learning objectives, it provides clear, meaningful, and personalized feedback for students related to achievement of the course learning objectives and helps them identify their weaknesses in the course: Atwood \& Siniawski (2014).

\section{Introduction to the first semester course material science in mechanical engineering at HTW}

Material Science is taught as a compulsory course during first semester undergraduate study subjects such as mechanical, automotive and economical engineering at HTW Berlin based on the "design-led" teaching approach: Ashby et al. (2013), Pfennig (2016-1, Pfennig (2016-2) (figure 1). To prepare students for their role as a maker of things they begin to investigate and learn with a strong practical motive and critically discuss materials, properties, alternative materials and processes as well as the underlying physics and chemistry.



Figure 1. ,science-led-approach“ and ,, design-led-approach“ modified from: Ashby et al. (2013). 
Teaching in "inverted classroom" szenarios: Berret (2012), Brame (2015), Fischer and Spannagel (2012), Braun et al. (2012), Pfennig (2016-1) is a method to let the students study the science on their own and then take time to discuss their questions leaving time to work on extended hands on lectures or exercises in class. Peer instruction (Simon et al., 2010) is used to assess the learning progress prior to each class. The method of "blended learning" was found to apply well. Scientific peer-to-peer lecture films: Pfennig (2016-1) and micromodule lectures provided via the content management system moodle are the main learning resources. In addition different teaching materials e.g.: worksheets and worked solution, mindmaps, glossarys, memory sheets, online tests and web-basedtrainings WBT are available: Pfennig and Böge (2015), Pfennig (2016-1). Because different learning styles are considered students coming from different scientific and ethnic backgrounds are enabled to study during online periods in equal measure. In class there was time for hands on excercises, discussions, group work and mastering difficult questions. These learning materials were partly contributed by students during material science projects. This peer-to-peer approach: Colorado (2015) and peer reviewing: Ware (2015), Wilson (2012) allows for high teaching standards: Pfennig (2016-1).

In this context the assessment of students learning outcome on one single final exam as ususal does not strike as appropriate. The grading system chosen directly connects the course assessments to the course learning objectives and are not a only a series of separate course assignments: Carberry et al. (2012).

\section{A new course structure and grading system}

It was therefore necessary to decentralize the course assessment and establish step-by-step grades with regard to the learning objectives over the 12 to 16 weeks of the semester. Moodle provides an excellent basis to establish graded activities that are followed each lecture or theme (figure 2). All semester activities count to 50 points, the final moodle exam based on tests during the semester counts for 10 points (in sum 60). Therefore the following activities were weighted appropriately and implemented as compulsory summing to 60 possible points in total:

- 3 Quizzes = 12 questions (each 1$)$

- 9 Medium tests 20-40 questions (each 2)

- 1 Final test (70 questions) (10)

- 4 Glossary entries (each 1)

- 14 graded lectures (each 3 to 5)

- 3 homework assignment (each 2)

- 2 Forum entries (each 2) 


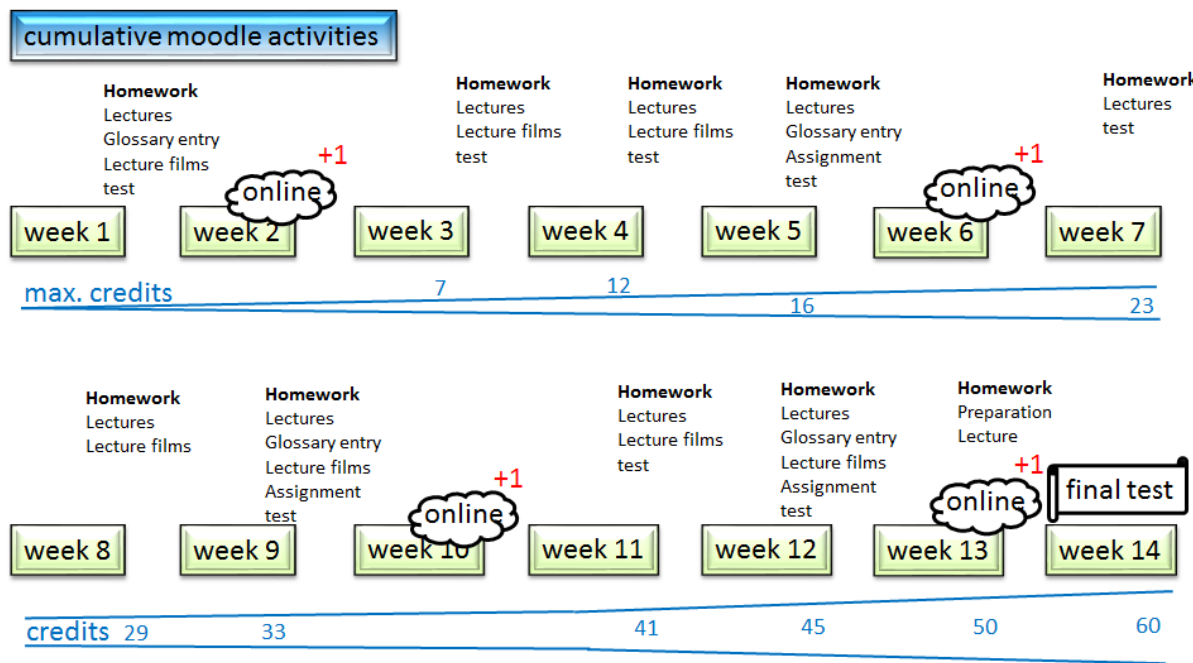

Figure 2. Workflow, Grading and Assignments in the moodle based materials science course (5 ECTS)

Alternatively the students could choose to take a final exam isochronic to the final moodle course test worth also 60 points (figure 2). One week prior to the final exam the students had to sign wether they wanted to be assessed based on their moodle results of take the final exam. Students found this advantageous because they could make their choice the last minute depending on their grade points until the time of the final exam. To prevent students from stopping to work in the middle of the semester most of the points were assigned in the last 3 weeks before final exam (60 points) or final moodle exam (10 points). The final exam counts for all students transferring in the middle of the semester, repeating students and those coming from different study subjects without access to present hours. Presence time was 1 day, 4 hours/week. HTW regulation allows for $20 \%$ e-Learning in a presence course, therefore the blended learning concept applies well.

\section{Example 1: Results of a problem on phase diagrams in final exam}

In summer semester 2015 the moodle course was still a voluntary "add-on". In winter semester 2015 first activites counted for extra grade points and were compulsory to access the final exam. For both semester the same problem on phase diagrams was given to students in the final exam. This problem aimed at solving practical problems regarding microstructure and the correct use of phase diagrams. Similar problems were given to the students in winter semester 2015 after studying the theory at home, whereas in summer semester phase diagrams was taught in class. In the final exam students scored $43 \%$ averagely of the phase diagram related problem in SS2015 where no inverted classroom szenario was applied and 68\% averagely in SS2015/16 where phase diagrams was taught using the inverted classroom approach (figure 3). 


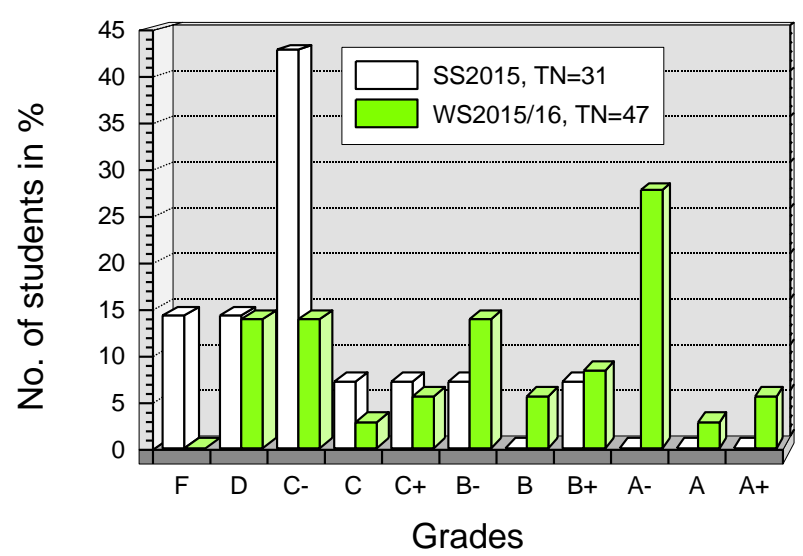

Figure 3. Results of compulsary problem on phase diagrams in final exam, left SS2015 (front teaching), right WS15/16 (inverted classroom). Purposely for reason of comparison the problem was the same in both semester.

Wether students in summer 2016 had better natural abilities or studied better could not be evaluated. However, results showed clearly that students had a much better understanding how to practically work with phase diagrams compared the previous semester (figure 3 ).

\section{Example 2: Comparing course results obtained via final exam and cumulative moodle course assessment}

Final grades in material science of winter semester 2015/16, with a final exam in the end of the semester as means of assessment, were compared to grades students achieved in the cumulative moodle course of summer semester 2016. Prior to thes assessment students had to sign a form that their grade will be calculated from their results throughout the semester.



Figure 4. Results of compulsary final online exam in material science, left WS15/16, right SS2016 
Avaragely students scored 39 (C+) out of 60 possible points in 2015/16 and 43 (B) (in 2016 (figure 4). On first sight this does not count for massive improvement, but the median differs lot more: 43.5 (B) in 2015 and 49 (A-) in 2016. Still, most important is the grade distribution: The moodle course assessment offers more students access to good grades, such as A- to A+ compared to the course assessment via final exam. Moreover, students with migration background scored higher and achieved better results than students belonging to the same group the previous semsesters.

\section{Evaluation of the moodle course concept}

In summer semester 201644 out of 52 students chose the course assessment via cumulative moodle activities. 2 students chose a final exam and 6 students were lost during the first semester. Grades divided into more than 25 single micro grades that are weighed and summed offers the lecturer to be less biased during grading: CSU (2015) and therefore students grades are more substantial.

\subsection{Students`opinion}

Students found lecture videos and micro modules as main source of the "inverted classroom concept" appealing because they are reusable with no regard to place and time. The possibility to repeat whole lectures as well as small parts helped to meet the individual learning velocity. They found homework very useful in terms of self organization and learning complicated scientific issues and getting to the bigger picture of material science. Some students did not like homework, because they were forced to study instead of just pushing the work load ahead of them. Still, the biggest advantage of this grading system was found to be the transparent level of points throughout the semester letting students directy know the grade they are achieving at the moment reassuring them of their learning skills. And even more important was the fact, that the studying time did not push towards the end of the semester, but was equally distributed in time throughout the course.

\subsection{Teachers`opinion}

Pro: Because during selfstudying students were very motivated to learn, they share their knowledge helping others and contributing to solving problems in class. The pleasant atmosphere in class enabled students to apply their knowledge solving even more complex material science problems. During the semester students were given more responsibility for their learning progress which encourages critical thinking: CSU (2015), Lord (2012); that results in deeper learning outcomes: Goto and Schneider (2010), Simon et al. (2010). It was fun teaching lively and critical students who were eager to enrich the material science class.

The depth of scientific knowledge with wich students responded in forums was very high. In addition their discussion skills with regard to scientific knowledge were enhanced. 
At-risk students that might fail the course could be identified very early and lecturers have the possibility to accompany their further learning progress more closely and -if necessaryprovide detailed guidance. The possibility to work in small groups during class enables the teacher to provide help at the exact level the students learning has progressed and immediately supporting those who did not meet the requirements for a specific topic. Because the assignment is clear and most of the moodle acitivites are available throughout the entire semester, unprepared students studied very well after the contact time and achieved good grades.

Students with migration background and language problems in class in general showed good to very good results in tests and assignment when they were given enough time to overcome their language problems. Because they had a chance to score high in this class we found that especially these students put a lot of effort into their studies. This reduced the diversity in learning outcome during the semester and enhanced homogeneity. Also, students who had to work or take care of family members could participate without knowledge loss, because the moodle course offers time and place independent studying.

Contra: Students who only want to pass the course might not work constantly towards the end of the course once they achieved 30 points. It takes effort to motivate this specific group. However, increasing the amount of points adding to the course towards the end prevents students from dropping out early.

The amount of time to prepare moodle acitivies necessary to generate a stand alone moodle course initially along with lecture films meeting different learning types and the needs of a diverse first year material science class is outrageously high. Also, the time spent on emails answering question, giving advice or organizing has raised in addition to the time that has to be spent with the daily design and correcting and commenting on assignments. To benefit from this new teaching method the workload of the lecturer does not douple but honestly rather triples.

\section{Conclusion}

Inverted classroom szenarios based on micro lectures in material science and peer-to-peer lecture films were estabilished and provided via moodle. The blended learning approach gives students the chance to cumulative add micro-grades via multiple activities that are summed to obtain the overall course grade. Improved learing outcomes are demonstrated in high quality class discussions and in better grades. The majority of students agreed on enhanced study skills when forced to study throughout the entire semester instead of learing intensely towards the end of the semester. Enthousiastic students were able to solve enhanced problems and contribute to many issues in more depth. 


\section{References}

Ashby, M., Shercliff, H., Cebon, D.: Materials Engineering, Science, Processing and Design, 2013: ISBN-13: 978-0080994345, 2013: ISBN-10: 0080994342, Pub date: Oct 02, 2013 (3rd edition).

Atwood S.A., Siniawski M.T., Using standards-based grading to effectively assess projectbased design courses, The american society for engineering education annual conference, Indianapolis, IN (2014).

Berrett, D.: How 'flipping' the classroom can improve the traditional lecture, The Cronicle of Higher Education (2012).

Brame, C.J.: Flipping the Classroom, http://cft.vanderbilt.edu/files/Flipping-theclassroom.pdf, call: 09/2015.

Braun, I. et al., Inverted Classroom an der Hochschule Karlsruhe - ein nicht quantisierter Flip, Beitrag zu „Das Inverted Classroom Model: Begleitband zur ersten deutschen ICM-Konferenz“", Jü Handke, Alexander Sperl (Hrsg.), Oldenbourg Verlag, 2012.

Carberry A.R., Siniawski M.T., Dionisio J.D.N., Standards-based grading: Preliminary studies to quantify changes in affective and cognitive student behaviors, IEEE Frontiers in education conference, seattle, WA (2012).

Colorado State University, Using Peer Teaching in the Classroom, (2015), http://teaching.colostate.edu/tips/tip.cfm?tipid=180.

Fischer, M und Spannagel, C: Lernen mit Vorlesungsvideos in der umgedrehten Mathematikvorlesung, in Desel, J., Haake, J.M. und Spannagel, C. (Hrsg.), DELFI 2012, Die 10. E-Learning Fachtagung Informatik der Gesellschaft für Informatik e.V., S. 225-236, Bonn: Köllen Druck + Verlag,

Goto, K. \& Schneider, J., Learning through teaching: Challenges and opportunities in facilitating student learning in food science and nutrition by using the interteaching approach. Journal of Food Science Education 9(1) (2010) 31-35.

Guskey T. R. and Pollio H. R., Grading Systems - SCHOOL, HIGHER EDUCATION, Grading Systems - SCHOOL, HIGHER EDUCATION - Students, Grades, Teachers, and Learning, Education Encyclopedia (2012) - StateUniversity.com.

Heywood J., The evolution of a criterion referenced system of grading for engineering science coursework, IEEE Frontiers in education conference, Madrid, Spain (2014).

Lord, T., 101 reasons for using cooperative learning in biology teaching. The American Biology Teacher 63(1) (2012) 30-38.

Marbouti F., Diefes-Dux H. A., Madhavan K., Models for early prediction of at-risk students in a course using standards-based grading, Computers \& Education 103 (2016) $1-15$.

Pfennig, A. and Böge, A., A material science course based on a blended learning concept using an interdisciplinary approach at HTW Berlin, "e-Learning'15", 11-12 September 2015, University of Applied Sciences, Berlin, Germany.

Pfennig, Anja and Hadwiger, Paul, Peer-to-peer lecture films - a successful study concept for a first year laboratory material science course, Procedia - Social and Behavioral Sciences 228 (2016) 24-31 
Pfennig, Anja, Inverting the Classroom in an Introductory Material Science Course, Procedia - Social and Behavioral Sciences 228 (2016) 32-38

Sadler D. R., Interpretations of criteria- based assessment and grading in higher education, Assessment \& Evaluation in Higher Education, 30(2) (2005) 175-194, online 2010

Simon, B., Kohanfars, M., Lee, J., Tamayo, K, \& Cutts, Q., Experience report: peer instruction in introductory computing. Proceedings of the 41st ACM Technical Symposium on Computer Science Education (2010) 341-345.

Ware M., Peer review: benefits, perceptions and alternatives, Publishing Researching Consortium, www.publishingresearch.net/documents/PRCsummary4Warefinal.pdf, call 09/2015

Wilson J., Peer review, The nuts and bolts, A guide for early career researchers, 2012, http://www.senseaboutscience.org/data/files/resources/99/Peer-review_The-nuts-andbolts.pdf 